\title{
Spine surgery and clinical research in Italy
}

\author{
Claudio Lamartina - Giuseppe M. V. Barbagallo
}

Received: 6 September 2013/Accepted: 6 September 2013/Published online: 24 September 2013

(C) Springer-Verlag Berlin Heidelberg 2013

In this fourth special issue dedicated to the Società Italiana di Chirurgia Vertebrale, GIS, the so-called Italian Supplement of the European Spine Journal, the reader can find a short selection of the current surgical trends as well as of the spine-related research activities in Italy.

The concept of research in the spine field is broad and the last decade has been testimony to worldwide significant efforts [1, 2] both in basic [3-5] and in clinical research activities [6-9], aimed at ultimately improving patients' care. Indeed, either basic or clinical research has been fostered with the aim to arrive at clinically useful conclusions. Such strategy has been adopted by all major national and international spine societies. In Italy, like in many other countries, spine surgery is continuing to undergo profound changes, with the stable number of orthopedic spine surgery and that of spine neurosurgeons rising. This is not only a "social change" but, most importantly, a "cultural" one. Neurosurgeons are traditionally trained in microsurgical techniques and soft-tissue handling surgical procedures; however, they may lack a specific knowledge of bone biology and biomechanics, two cornerstones of spine surgery, which are well known to orthopedic surgeons. Such intrinsic differences may also be one of the causes influencing the apparently different clinical and surgical attitudes, i.e., spinal neurosurgeons being prone to adopt and boost minimally invasive techniques and computer-guided surgery, while orthopedic spine surgeons favoring more biological and biomechanical topics, like the sagittal balance. Indeed,

C. Lamartina $(\bowtie)$

II Spine Surgery, IRCSS Istituto Ortopedico Galeazzi,

Via Riccardo Galeazzi, 4, 20161 Milan, Italy

e-mail: c.lamartina@chirurgiavertebrale.net

G. M. V. Barbagallo

Division of Neurosurgery, Policlinico "G. Rodolico" University

Hospital, Via S. Sofia, 78, 95123 Catania, Italy this is only an apparent distinction, as it is always more common to find spine specialists harboring the different competencies [10].

The papers accepted for publication in this Supplement deal mostly with clinical research topics and span across all spinal topics (degenerative, deformity, trauma and tumor). A quick look at this volume's index will make the reader aware of the significant attention dedicated by Italian spine surgeons to the sagittal balance topic and, in general, to the deformity field. The benefits and risks of contemporary techniques, like computer-guided and minimally invasive surgeries, particularly in trauma patients, have been analyzed in other papers. Studies dealing with surgical and radiological techniques used in cervical spine degenerative disease, focusing also on less common conditions, or in spinal tumor cases have been included as well.

The basic research section of the Supplement hosts two interesting studies, which are just an example not only of the interest in basic research pursued by some of the main national spine centers, but also of the growing attention dedicated by younger researchers to such field, in particular to those topics related to the intervertebral disc degeneration and to stem cell-based therapies. Indeed, it is recent the establishment of an Italian spine basic research award, named BioSpina (http://www.biospina.com).

Lastly, the presence in this Supplement of studies presented at 2012 GIS meeting by French spine surgeons or resulting from the scientific collaboration between Italian spine surgeons and other European colleagues is an example of the continuous cultural exchange, which will continue to positively influence the spine care activities in Italy and, at the same time, to make others aware of the Italian know-how.

Conflict of interest None. 


\section{References}

1. Mulholland RC (2013) The Michel Benoist and Robert Mulholland yearly European Spine Journal Review: a survey of the "surgical and research" articles in the European Spine Journal 2012. Eur Spine J 22(2):250-259

2. Amiri AR, Kanesalingam K, Cro S, Casey AT (2013) Level of evidence of clinical spinal research and its correlation with journal impact factor. Spine J 13(9):1148-1153. doi:10.1016/j. spinee.2013.05.026

3. Maerz T, Herkowitz H, Baker K (2013) Molecular and genetic advances in the regeneration of the intervertebral disc. Surg Neurol Int 4(Suppl 2):S94-S105

4. Kepler CK, Ponnappan RK, Tannoury CA, Risbud MV, Anderson DG (2013) The molecular basis of intervertebral disc degeneration. Spine J 13(3):318-330

5. Vo N, Niedernhofer LJ, Nasto LA, Jacobs L, Robbins PD, Kang J, Evans CH (2013) An overview of underlying causes and animal models for the study of age-related degenerative disorders of the spine and synovial joints. J Orthop Res 31(6):831-837

6. Roth AK, Bogie R, Jacobs E, Arts JJ, van Rhijn LW (2013) Large animal models in fusionless scoliosis correction research: a literature review. Spine J 13(6):675-688

7. Van Oldenrijk J, van Berkel Y, Kerhoffs GM, Bhandari M, Poolman RW (2013) Do authors report surgical expertise in open spine surgery related randomized controlled trials? A systematic review on quality of reporting. Spine 38(10):857-864

8. Fischer CR, Cassilly R, Cantor W, Edusei E, Hammouri Q, Errico $\mathrm{T}$ (2013) A systematic review of comparative studies on bone graft alternatives for common spine fusion procedures. Eur Spine J 22(6):1423-1435

9. Konig V, Eichen PM, Achilles N, Mosges R (2013) A systematic review of RCTs with nucleoplasty - an update. Pain Physician 16(1):E45-E46

10. Kanat A, Yazar U (2013) Spinal surgery and neurosurgeon: quo vadis? J Neurosurg Sci 57(1):75-79 